\title{
Feministas, mulheres e esporte: questões metodológicas
}

Hugo Lovisolo* Antonio Jorge Soares* Tiago Lisboa Bartholo ***

\begin{abstract}
Resumo: O artigo discute aspectos da perspectiva crítica particularmente relevante no debate sobre gênero: denúncia, "cotismo" e efeitos epistemológicos ou de conhecimento, a partir do debate instalado sobre a participação feminina no futebol. A escolha deste esporte se deu por sua importância na e para a cultura brasileira e, sobretudo, porque autoras e autores investiram criticando representações, práticas cujas formas de participação seriam controladas pelos homens. Conclui-se, observando, que além da crítica ou da denúncia à discriminação, baseada no 'cotismo', não há a emergência de novidades de conhecimento a partir da perspectiva de gênero.

Palavras-chave: Feminismo. Esportes. Eqüidade. Identidade de Gênero.
\end{abstract}

\section{EPISTEMOLOGIA E POLÍTICA NA PERSPECTIVA DE GÊNERO}

A perspectiva crítica de gênero no campo do esporte, embora não apenas nesse, parte de duas teses explícitas ou implícitas. A primeira diz que as representações, normas e hábitos que orientam as formas de participação das mulheres nos esportes foram gerados pelos homens que, paradoxalmente, foram educados principalmente por mulheres, no lar e na escola. Temos que reconhecer, então, que as educadoras reproduziam as crenças masculinas

* Doutor em Antropologia Social, Professor do PPGEF/UGF, Professor da FCS/UERJ, vicecoordenador do Grupo de Estudos Esporte Cultura/CNPq. E-mail: lovisolo@globo.com "* Doutor em Educação Fisica, Professor do PPGEF/UGF, Professor do CEFD/UFES, mem bro do Grupo de Estudos Esporte Cultura/CNPq e pesquisador do CNPq. E-mail: ajsoares@globo.com

*** Mestrando do PPGEF/UGF e bolsista do CNPq.

Movimento, Porto Alegre, v.12, n. 03, p. 165-191, setembro/dezembro de 2006. 
produzidas pelos homens. ${ }^{1}$ A segunda indica que essas construções objetivam o controle ou poder sobre as mulheres por parte dos homens. Da forma em que é formulada a segunda tese, ela supõe que a vontade de controle ou poder sobre as mulheres formaria parte da natureza masculina. ${ }^{2}$

Nem sempre as autoras, e alguns autores que parecem aderir à perspectiva de gênero ${ }^{3}$, explicitam ambas as teses; por vezes elas funcionam juntas ou isoladamente como pressupostos das elaborações. A vontade de denúncia, da construção e do controle é basilar na literatura de gênero, e não poderia ser de outra forma, quando se parte da existência do domínio e da aspiração de emancipação. A vontade de denúncia invadiu a mídia, formando parte daquilo que denominamos de "politicamente correto". ${ }^{4}$ Forma parte, então, do objetivo político da revolução feminina, vista como continua no tempo e em crescimento no espaço. Contudo, a vontade de denúncia pode fechar as janelas epistemológicas da perspectiva de gênero, como veremos adiante.

O corolário das teses diz que a perspectiva de gênero poderia gerar novas representações orientadoras das relações sociais e, por

${ }^{1}$ Em esquema de reprodução desta natureza apenas algumas mulheres iluminadas poderiam quebrar o ciclo. Procurar por elas, ou inventá-las, é fundamental para a perspectiva de gênero de viés feminista.

${ }^{2}$ Como a maioria dos trabalhos se refere aos homens em geral, sem estabelecer distinções de qualquer natureza, apenas a natureza humana poderia ser fundamento de suas atitudes. Assim, surgem implicações universalistas ou naturalistas mesmo em trabalhos que se pretendem desconstrutivos ou sob o domínio do culturalismo. Na comparação relacional, entre homens e mulheres, o perigo de que as "virtudes" femininas sejam naturalizadas está sempre presente num mecanismo de transformação do cultural em natural.

${ }^{3}$ Aqui a perspectiva de gênero se confunde com a perspectiva feminista da denúncia da Aqui a perspectiva de gênero se conúncia da opressão, consciente ou inconsciente, do homem sobre a mulher. Os estudos confundem a análise com os desejos de intervenção no sentido de educar os homens. Ver as críticas de Badinter (2005) e Kupper (2002) sobre as essencializações da perspectiva culturalista do discurso identitário de gênero e raça.

${ }^{4}$ A expressão "politicamente correto" foi uma invenção dos conservadores americanos diante do avanço das lutas igualitaristas das "minorias". O politicamente correto, em suas diversas manifestações, recortaria, principalmente, o poder e interesses dos homens brancos.

Movimento, Porto Alegre, v.12, n. 03, p. 165-191, setembro/dezembro de 2006. 
certo, das próprias práticas esportivas. Não conhecemos pesquisas que evidenciem mudanças em algum esporte a partir da perspectiva de gênero - além da maior participação de mulheres - nos valores orientadores, nas regras, nos estilos. Ou seja, se lhe atribui um caráter revolucionário ou reformador, epistêmico e político que, talvez seja de lamentar, não parece estar operando mudanças na prática. Tal corolário se relaciona estreitamente com os dois objetivos principais das intervenções de gênero: o epistemológico e o político. Vejamos alguns dos entendimentos desses objetivos.

\begin{abstract}
O que uma quantidade enorme de bons trabalhos tem mostrado é que, quando se aborda qualquer questão - seja ela histórica, sociológica, geográfica, etc. - a partir de uma perspectiva de gênero, ela adquire outro sentido. Ou seja, como um modo de análise, uma metodologia, gênero é uma categoria que nos faz pensar de modo diferente sobre qualquer tema. (MITCHELL, 2000, p. 8)
\end{abstract}

Nosso propósito será o de observar de forma inicial nesse texto como, e em qual medida, a perspectiva de gênero na análise das ciências humanas e sociais, no campo do esporte, principalmente no do futebol no Brasil, geram novos ou outros sentidos. ${ }^{5}$ Enfim, como a perspectiva de gênero faz pensar de modo diferente, sobre suas questões, a aquelas tradicionalmente elaboradas pelos homens. Observemos três aspectos relevantes da argumentação de Mitchell (2000).

O primeiro acredita que a perspectiva de gênero não seja sempre prioritária, embora possa estar presente na análise de qualquer situação ${ }^{6}$; essa é uma ressalva que não está presente na cita-

\footnotetext{
${ }^{5}$ A perspectiva de gênero teve profunda incorporação, embora crítica, na produção das Pós-graduações em Educação Física.

Juliet Mitchell tem uma produção intelectual altamente significativa, destacamos "Women - The Longest Revolution", e foi participante ativa da renovação do marxismo realizada pelo grupo da "New Left". Ela entende que, na atualidade, a situação das crianças deve ser a principal preocupação das feministas (Mitchell, 2000).
}

Movimento, Porto Alegre, v.12, n. 03, p. 165-191, setembro/dezembro de 2006. 
ção anterior, porém é importante. Em algumas situações, a perspectiva de classe, por exemplo, deve ser priorizada (ou a perspectiva dos idosos ou das crianças?). Contudo, poder-se-ia afirmar que mesmo nos conflitos de classe seu entendimento e as formas de participação deveriam ser englobados por uma perspectiva de gênero. Assim, a perspectiva de gênero, sob o ponto de vista do conhecimento e da ação, continuaria sendo priorizada.

O segundo informa que a perspectiva de gênero é um modo de análise, uma metodologia. Esta afirmação tem um ar cientificista, pois parece haver garantias em aplicar tal modo de análise ou metodologia. ${ }^{7} \mathrm{O}$ terceiro, sua definição tem uma restrição ou ressalva: o "outro sentido" apenas aparece nos "bons trabalhos". O entendimento leva na direção da anedota atribuída a Lévi-Strauss, que elogiou o autor de uma pesquisa dizendo que era uma bela elaboração estruturalista. O autor respondeu que ele não era estruturalista. Lévi-Strauss não arredou pé, declarou que todo bom trabalho é estruturalista. Ou seja, corremos o risco de que qualquer bom ensaio ou pesquisa sobre mulheres seja considerado de gênero ou feminista. No reverso, qualquer trabalho que fale de mulheres e não faça aparecer o "outro sentido" não poderá ser considerado "bom" e nem de gênero. O que está em questão não é o valor das diversas e numerosas contribuições realizadas por mulheres no campo da pesquisa e nem a relação de respeito ou desprezo que os homens têm com elas. Os pontos a serem considerados são: a) se as contribuições resultam da presença da perspectiva de gênero na produção no campo restrito da pesquisa em ciências sociais e humanas e b) se resultam em "outros sentidos", agregamos outros valores.

Assim, se no caso do futebol não encontramos novos senti-

${ }^{7}$ Isto não é muito diferente de pensar que a solução de qualquer problema reside na aplicação do "método experimental". A diversidade ou pluralidade metodológica desaparece.

Movimento, Porto Alegre, v.12, n. 03, p. 165-191, setembro/dezembro de 2006. 
dos, novos conhecimentos, teremos duas opções: a) pensar que os trabalhos não são bons e b) discutir se o pressuposto da produção do novo, sob a perspectiva de gênero se aplica a "qualquer questão" como Mitchell (2000) afirma. A questão substantiva é: a perspectiva de gênero fez "avançar" o conhecimento e julgamentos, éticos e estéticos, sobre o futebol, por exemplo? Observamos que nem sempre o futebol teve o prestígio intelectual que hoje tem, pois faz poucos anos atrás eram muitos os que partilhavam a opinião de ser o futebol uma variante do "ópio do povo", antes da ocorrência daquilo que foi denominado de "virada romântica" nesse campo (Lovisolo, 2002), portanto, se ruim para homens, pior para mulheres. ${ }^{8}$ De fato, nem sempre foi aceito o valor do futebol como prática social e enquanto objeto de pesquisa.

O objetivo político, por sua vez, encontra sua expressão no universo das conquistas femininas: "[...] A grande conquista do feminino foi organizar a entrada da mulher como sujeito maior da história, a mesmo título que o homem" (MURARO, 2000, p. 3).

O movimento feminista conquistou tudo de mais importante para a mulher. É claro que ainda falta avançar em muitos pontos, as conquistas não estão concluídas. No Brasil, as mulheres alcançaram a igualdade plena de direitos com os homens na Constituição Federal de 1988. Temos uma constituição moderna, igualitária, cidadã. Na prática, a igualdade ainda não é completa, mas estamos caminhando para isso. (ELUF, 2000, p. 3)

O principal eixo da política feminista foi o de alcançar a

8 Uma leitura de Sebrelli (1981) será suficiente para convencer aqueles que não tiveram a experiência da crítica radical ao futebol realizada, sobretudo, por intelectuais filiados à tradição marxista. Como é sabido, Marx caracterizou a religião como "ópio do povo". As paixões do futebol seriam tão fortes como as religiosas e desviariam da luta pela emancipação. Analogamente, poderiam desviar as mulheres de suas funções socialmente construídas.

Movimento, Porto Alegre, v.12, n. 03, p. 165-191, setembro/dezembro de 2006. 
igualdade civil, política, econômica e social. A luta pela igualdade foi acompanhada pela procura do reconhecimento do valor da participação da mulher na história, tanto na esfera privada quanto na pública. Assim, reconhecimento/valorização e igualdade tornaram-se faces de uma mesma moeda. As mulheres assumiram bandeiras construídas e levantadas pelos homens e, não raro, contaram em suas lutas com o apoio de parcelas significativas dos mesmos.

Antecipemos que, no caso do esporte no Brasil, domina a aceitação do argumento de Mourão (1998), segundo o qual a entrada da mulher no esporte se deu por "infiltração", "subrepticiamente", pelas bordas. Isto significa que foi um alargamento e aprofundamento da participação sem organização da ação coletiva, isto é, sem a presença de organizações e movimentos que lutassem pela incorporação. Observamos que o termo "infiltração", embora possua significado geológico e médico, também teve ampla utilização na linguagem militar e político sindical, em campos, então, onde se realizam combates, se travam lutas; este não parece ser o caso da participação das mulheres no esporte no Brasil. Cremos que se deva a esse sentido "guerreiro" do termo parte significativa da aceitação da tese, embora não se descrevam lutas e, muitas vezes, se apresentem os discursos masculinos a favor da ginástica e da prática esportiva para mulheres, ainda que justificados por valores como beleza, da feminilidade da maternidade (filho sadio em mãe sadia!). Ver, como exemplo, as elaborações de Goellner (2003).

Entretanto, em outra linguagem, poderíamos dizer que estamos diante de processos de reconhecimento e participação, de incorporações que, como é típico no Brasil, foram realizadas de cima para baixo, das elites em direção do povo ou dos que mandam para os que obedecem. Dos homens, então, em relação às mulheres? As evidências, como o discurso dos higienistas, a educação física escolar, a formação de professoras de educação física, o estímulo para as mulheres participarem da vida social e esportiva dos clu-

Movimento, Porto Alegre, v.12, n. 03, p. 165-191, setembro/dezembro de 2006. 
bes, a organização de eventos ginásticos e esportivos femininos, como os promovidos por Mario Filho', entre outros, parecem indicar que podemos relativizar a infiltração e suas formas sub-reptícias. Sem dúvida, essa ação de cima para abaixo, dos homens para as mulheres, foi atravessada pela distinção masculino e feminino, com seus respectivos valores e a promoção foi mais na direção da prática amadora do esporte pelas mulheres, com objetivos sociais de maximizar a saúde, a beleza e ajudar as funções de reprodução, dentre outras..$^{10}$ Contudo, como teria sido canônica no Brasil, a incorporação foi de tipo conservador ou de cima para abaixo. Então, dos homens para as mulheres.

Partilhando o ponto de vista do caráter revolucionário do feminismo e suas valorações, gostaríamos de observar que há silêncio feminista quando a desigualdade é favorável à mulher e que o valor da igualdade pode levar na direção do formalismo do "cotismo" 11 e suas duas facetas negativas: a seleção arbitrária de sua aplicação e a ausência da discussão ética e estética do valor da participação. ${ }^{12}$

Vejamos alguns exemplos da seleção arbitrária. No caso do Brasil, não se reivindica que na Constituição Brasileira a mulher tenha a obrigação no serviço militar como os homens, embora a

\footnotetext{
${ }_{9}^{9}$ Mario Filho foi jornalista esportivo - considerado um dos construtores de um estilo de jornalismo- e proprietário do Jornal dos Sports. Utilizava seu jornal como um espaço de promoção de concursos, desfiles e atividades e competições esportivas para crianças, adolescentes e adultos, de ambos os sexos.

${ }^{10}$ Os programas de treinamento esportivo e a modelagem corporal, embora formem parte de tribos da educação física (Lovisolo, 1997), por vezes, são articulados pelo atleta orientado para o desempenho em alcançar, entre outros objetivos, a "proporcionalida entado para o desempenho em alcançar, entre outros objetivos, a "proporcionalidade das formas" ou "compensar" efeitos negativos da especialização. Veja-se como exemplo os depoimentos das mulheres surfistas em Knijnik e Souza (2004). Todavia, a crítica que esporte poderia tornar o corpo desproporcional estava nos jornais do início do século, ver (Pereira, 2000:, p. 48-9)

11 Por "cotismo", um neologismo, entende-se a reivindicação de igualdade proporcional em qualquer campo e nível organizativo das atividades.

${ }^{12}$ A "seleção arbitrária" é o que Badinter (2005, p. 69-73) denomina de "omissões". Sobre
} o "valor das participações" ver os artigos de Simmel (2002).

Movimento, Porto Alegre, v.12, n. 03, p. 165-191, setembro/dezembro de 2006. 
Constituição enfatize a igualdade..$^{13}$ Em outro plano, a produção acadêmica de gênero ou a militância feminista não se manifesta a favor da igualdade nas condições de aposentadoria, depois de tudo, com quase sete anos a mais de esperança de vida e cinco a menos no tempo de trabalho para a aposentadoria, deveriam existir denúncias sobre esse evidente beneficio enquanto produto do 'machismo dominante' ou da proteção da capacidade reprodutiva da sociedade. De novo, a lei específica está indo contra o espírito geral, igualitário, da Constituição. Aplicar a proporcionalidade da reivindicação "cotista" implicaria em aposentadoria mais tardia ou em uma contribuição maior por parte das mulheres. ${ }^{14}$ Se existe um preconceito sobre a fragilidade feminina, nos casos mencionados lhes é favorável.

Não houve comentário contrário à obrigatoriedade da quota de candidatas femininas para os cargos políticos, embora as dirigentes políticas mulheres de prestígio sejam, na maioria das vezes, produtos de suas trajetórias e ligações políticas e não efeitos da lei. Nesse caso, o sofrimento de algumas posições feministas é que o aumento das mulheres no poder não significa necessariamente coalizão em favor da 'causa' das mulheres. ${ }^{15} \mathrm{Na}$ mesma

\footnotetext{
${ }^{13}$ Diz o artigo Art. 143. O serviço militar é obrigatório nos termos da lei. $\S 1^{\circ}$ - às Forças Armadas compete, na forma da lei, atribuir serviço alternativo aos que, em tempo de paz, após alistados, alegarem imperativo de consciência, entendendo-se como tal o decorrente de crença religiosa e de convicção filosófica ou política, para se eximirem de atividades de caráter essencialmente militar. $\S 2^{\circ}$ - As mulheres e os eclesiásticos ficam isentos do serviço militar obrigatório em tempo de paz, sujeitos, porém, a outros encargos que a lei lhes atribuir (Grifo nosso).

${ }_{14} \mathrm{~A}$ diferença na esperança de vida entre homens e mulheres aumentou nos últimos anos. Os dados indicam que como produto da guerra entre gangues e com a polícia que faz suas vítimas entre adolescentes e homens jovens principalmente. Esta situação seria um suas vitimas entre adolescentes e homens jovens principalmente. Esta situação seria um exemplo na qual a perspectiva de gênero não teria caráter prioritário na análise. No entanto, como são os filhos que estão morrendo,
ter um caráter pacificador no terreno político?

ter um caráter pacificador no terreno político?
${ }^{15} \mathrm{Htun}$ (2001) não vê problema na falta de coalizão dos interesses e na ausência de um programa suprapartidário das mulheres, mas reclama que a política de cotas não é suficiente para produzir os efeitos desejados de participação das mulheres no poder nos países da América Latina em função dos sistemas eleitorais, das listas abertas em termos percentuais e dos controles partidários. Acredita que se deve produzir uma reforma eleitoral e políticas compensatórias para garantir o acesso das mulheres aos cargos eletivos e não simplesmente participar de listas partidárias. Observemos que essa é uma posição que reforça a política de vitimização pelo argumento da compensação. Ver também Badinter (2005).
}

Movimento, Porto Alegre, v.12, n. 03, p. 165-191, setembro/dezembro de 2006. 
direção, também não houve crítica sobre a transformação realizada de cima e aceita como benefício quando o COI instituiu cota de dirigentes femininas na gestão do esporte (MOURÃO; GOMES, 2004). Em nenhum momento, Mourão e Gomes (2004) se perguntam sobre o valor de ser dirigente esportivo: partem da visão "cotista" de que a participação deveria aumentar para algum dia ser igualitária e não realizam uma crítica das organizações esportivas, que mediante estatutos ou regimentos muito bem elaborados freiam a renovação, ou seja, fazem que para ser dirigente seja necessário estar dentro do 'esquema'. ${ }^{16}$ Acreditamos que a perspectiva de gênero, quando baseada no "cotismo" e sem discutir o valor daquilo que se aspira distribuir, cai nos mesmos sentidos, isto é, não agrega nada aos nossos entendimentos. Pior ainda, reproduz os sentidos e valores, conservadores ou não, gerados pelos homens, imita seus agires e, assim, dificulta a criação do novo.

O "cotismo" é a reivindicação para a igualdade proporcional na participação em qualquer esfera ou atividade social. Sob o ponto de vista do "cotismo" podemos, como faz Muraro (2000), ficar contentes porque as mulheres constituem $50 \%$ da população economicamente ativa, embora sem nos preocuparmos com a qualidade do trabalho. Diríamos, acompanhando parte da argumentação de Mitchell, (2000), que se essa participação, por exemplo, afeta negativamente a situação das crianças, teríamos que repensar o fundamento dessa alegria que se apóia na atribuição de valor que damos ao trabalho, à realização pessoal e à autonomia, entre outros. Não poderíamos ficar contentes se as mulheres representassem $50 \%$ das mortes violentas do Brasil ou dos acidentes de trânsito. Não atribuiríamos nenhum valor positivo a essa participação nas estatísticas. Ou seja, a participação igualitária não é um

${ }^{16}$ Já nos clubes institutos como eleição indireta, colégio eleitoral e outros favorecem permanência e rotação no poder daqueles que conseguiram alcançá-lo. A engenharia institucional conservadora é pensada para manter o poder entre grupos e indivíduos, não, especificamente, para frear a entrada das mulheres.

Movimento, Porto Alegre, v.12, n. 03, p. 165-191, setembro/dezembro de 2006. 
bem em si mesmo, depende do valor que lhe confere sentido. Sob o ponto de vista da igualdade proporcional teríamos que nos preocupar e fixar cotas a favor dos homens, se as mulheres tivessem uma participação na matrícula universitária superior ao seu peso na população? Deveríamos, portanto, discutir, como sociedade, o valor da participação em cada campo específico, levando em consideração os possíveis efeitos colaterais.

Observamos que no campo do esporte a perspectiva de gênero, afirmando o 'cotismo', corre o risco de ser a ele reduzida. Este ponto é particularmente importante. Assim, para superar a aceitação acrítica do 'cotismo', no campo da participação no futebol, teríamos que nos interrogar sobre o valor da mesma em cada contexto. Não conhecemos trabalhos no Brasil que reivindiquem $50 \%$ da participação das mulheres no body building ou de artistas femininas com o corpo trabalhado como uma fisiculturista. Pensamos que na perspectiva de gênero, que trata da relação da mulher com o futebol no Brasil, a discussão sobre o valor não é levada a sério. Mais ainda, quando boa parte dos homens manifesta suas opiniões, de fato divergentes sobre essa participação, essas são igualadas pela redução ao pré-conceito. Demonstraremos esta afirmação adiante.

\section{FUTEBOL E CULTURA MASCULINA}

Observamos que nem sempre o futebol teve o prestígio intelectual que hoje tem. Faz poucos anos eram muitos os que partilhavam a opinião de ser o futebol uma variante do "ópio do povo", mesmo na visão crítica ou progressista, portanto, se ruim para homens, pior para mulheres. ${ }^{17}$ A crítica ao futebol, feita por homens, não aparece na perspectiva crítica de gênero. Há duas insti-

${ }_{17}$ Perdurou na sociedade brasileira mesmo depois do profissionalismo que o futebol não era 'trabalho'. A oposição de futebol e estudos para os meninos sempre esteve presente na visão de mundo da classe média. Hoje a política de formação de talentos no futebol tenta a todo custo romper com essa imagem.

Movimento, Porto Alegre, v.12, n. 03, p. 165-191, setembro/dezembro de 2006. 
tuições com as quais os homens eram "ameaçados" para se afirmarem socialmente enquanto 'homens': o esporte e o exército e, dentro do primeiro, naturalmente o futebol, no caso do Brasil e de outros países..$^{18}$ Os adultos, pais, parentes e amigos entendiam que nessas instituições os homens se tornariam disciplinados, decididos, persistentes, fortes, valorosos, capazes de agir em conjunto e vários outros qualificativos (hoje no campo do esporte se usa o termo "assertivo"), além de divertirem-se, é claro. Esses qualificativos indicam como os homens deveriam ser, como devem ser formados e não como eles são. Os qualificativos estruturam um ideal social de masculinidade. Outros qualificativos eram e ainda são usados para o ideal social da formação das mulheres (beleza, dedicação, delicadeza, feminilidade e até vaidade). ${ }^{19}$ Assim, esporte e exército eram postos como lugares formadores de propriedades da masculinidade, talvez porque retiravam os meninos do universo cálido e protetor da vida privada onde dominava, supunha-se, a proteção e o afeto das mulheres, os beijos e os carinhos desejados que, em algum momento, afetavam o ideal de masculinidade, daí incômodo e vergonha.

As instituições de socialização do masculino (exército, esporte, rua etc.) foram lugares comuns para formação de homens. Talvez, tais representações sobre esse tipo de modelagem do caráter ainda estejam presentes como valores sociais, embora mais sussurrados ou praticados em silêncio do que propalados em alta voz como eram décadas atrás. Podemos pensar que o "macho" é hoje crescentemente acuado (GOLDENBERG, 2000). O desenvolvimento dessa crença ganhou destaque teórico e refinamento conceptual e empírico, nos trabalhos de Archetti (2003) e Alabarces

\footnotetext{
${ }^{18}$ Para um estudo etnográfico sobre a construção do corpo masculino nas escolinhas de futebol no Rio de Janeiro ver Guedes (1998).

${ }^{9}$ O interessante trabalho de Del Priore (2001) começa com a "denúncia" da crítica mora dos homens ao consumismo e a vaidade das mulheres. Termina quase que realizando a
} mesma crítica a mulher do presente na procura da beleza, juventude e saúde.

Movimento, Porto Alegre, v.12, n. 03, p. 165-191, setembro/dezembro de 2006. 
(2002). Nem sempre os produtos das pesquisas corrigem ou atacam preconceitos incorporados em crenças. Por vezes, apenas permitem melhor entendê-las e reconhecer que, talvez, poderíamos delas prescindir. Talvez 'prescindir' não seja o caso dos torcedores de futebol que Alabarces estudou e que professam o 'aguante'.${ }^{20}$ Contudo, o que importa salientar é que mesmo na literatura de gênero sobre o futebol se reconhece que o futebol em boa parte dos países se construiu como um lugar sagrado dos homens. Daí a recorrência, feita como brincadeira ou seriamente em nossa sociedade, de colocar no contrato de matrimônio o dia sagrado da pelada ou o de assistir o jogo. Qual o sentido, então, de invadir o universo sagrado do masculino? Qual o sentido cultural das mulheres em desejar afirmar um novo significado sobre esse esporte no contexto cultural brasileiro? Acreditamos que uma razão não dita é bem simples: o futebol transmite a imagem de um mercado de trabalho valorizado que além de retornos monetários permite um trabalho de qualidade, isto é, com prazer, como de modo geral o esporte. Assim, sugerimos que os valores para invadir o 'espaço sagrado dos homens' são os deles mesmo: o ganho econômico aliado à emoção e prazer do esporte. Algumas queixas feministas sobre o futebol apenas dizem: não ganhamos o mesmo que os homens! Não temos apoio! Não temos patrocínio! Nosso futebol não é apreciado como o dos homens (leia-se não tem o mesmo retorno que o dos homens)! Algumas destas declarações são habituais entre os esportistas em geral e mais ainda entre aqueles que praticam esportes sem o mercado do espetáculo. No campo do futebol as mulheres apenas querem ser iguais a homens?

Num passado recente, o salão de beleza das mulheres era visto como um lugar "sagrado" e privado. Não raramente havia mulheres que, também de brincadeira ou seriamente, estabeleciam

20 "Aguantadores e aguante", temas desenvolvidos por Pablo Alabarces. Em português talvez falariamos em "resistentes" e "resistência".

Movimento, Porto Alegre, v.12, n. 03, p. 165-191, setembro/dezembro de 2006. 
no "contrato" matrimonial que à tarde de sábado era destinada ao salão. Os homens que cuidassem das crianças ou fizessem qualquer coisa. $\mathrm{O}$ salão era um lugar misterioso com seus secadores de pé, luzes e paredes coloridas e imagens de belas mulheres com maravilhosos penteados. Os salões masculinos com suas navalhas, tesouras e máquinas de aço niquelado, estavam mais perto do açougue que daquela maravilha. Os cabelos não eram lavados nem secos com ar quente. A máxima sofisticação era o uso de toalhas quentes antes de barbear e a loção de "queimar" a pele rasurada pela navalha e, para alguns, a goma para o cabelo. $\mathrm{O}$ futebol era o tema dominante, embora a política e o sexo também apimentassem o cenário. Era um ambiente de "machos". Isto começou a mudar como efeito de "infiltrações". Surgiram os salões unisex. Entrou no cenário o xampu, o condicionador, os cremes, as colônias, a variedade de cortes e penteados. Enfim, os homens estavam tornando-se vaidosos ou "efeminados" para os mais conservadores, embora continuassem a falar de futebol. Os salões masculinos passam a serrem mais parecidos com os femininos. Não houve, entretanto, lutas para invadir o "local sagrado das mulheres", nem infiltração em seus espaços. De fato, continuaram a existir salões exclusivos de mulheres ou de homens e uma significativa parcela que atende a ambos. Não houve reivindicação de cotas. Apenas as coisas mudaram sob a influência dos negócios e da publicidade. A indústria cosmética começou a produzir para os homens; o creme anti-ruga tinha que ser diferente, pois as peles o eram. Os homens passaram a se cuidar de um modo mais "feminino". Inventou-se, recentemente, uma nova expressão: "metrosexual". ${ }^{21}$ Mudança não revolucionária, sem combate nem lutas, sem panfletistas nem analistas. "Infiltrações" ou mero efeito

21 "Metrossexual, ou "metrosexual" no original inglês, contração de heterossexual com metropolitano. Por definição é um empreendedor bem-sucedido, entre 25 e 45 anos, que vive nas grandes cidades e se preocupa com seu aspecto visual, se dedica a essa preocupação e gasta com ela, como fazem seus colegas gays do mesmo extrato social." A diferença fundamental é que a orientação do comportamento sexual é hetero.

Movimento, Porto Alegre, v.12, n. 03, p. 165-191, setembro/dezembro de 2006. 
do mercado no qual os inovadores procuram clientes novos, por vezes, para coisas não novas?

\section{FEMINISMO E FUTEBOL}

No caso do futebol no Brasil, o discurso de gênero parte da denúncia das proibições de sua prática na década de 40 e no regime da Ditadura Militar (de 1965 revogada em 1979).22 Outros esportes ditos violentos e de forte contato corporal foram proibidos, como diversos tipos de lutas. O que é fantástico é que a vontade de denúncia leva a cometer dois erros: o da falta de contextualização e a ignorância de que boa parte dos homens e das mulheres, com voz ativa, estavam divididos sobre a prática do futebol por parte das mulheres. Por ultimo, opera o não reconhecimento da vontade de penetração no futebol espetacular ou mediático, isto é, rentável.

Devemos enfatizar que muitos dos argumentos culturalistas, na ânsia da denúncia, acabam caindo no anacronismo e no essencialismo ao tomarem a perspectiva de gênero. Vejamos.

Em primeiro lugar, nenhuma das autoras feministas, que assume o ponto de vista do gênero, interroga-se sobre o contexto, sobre a formação política e ideológica que permite ao Estado intervir na vida privada, decretando aquilo que podemos fazer com os nossos corpos e nossas mentes. É diante dessa intervenção que deveria surgir o espanto que leva a reflexão, entender que o hábito da proibição vai além da questão feminista e, por isso, foram fecha-

${ }^{22}$ Devemos lembrar que o futebol de mulheres na Inglaterra teve início durante a $1^{\text {a }} \mathrm{Gran}$ de Guerra (1916-16) quando muitas jovens deixaram suas localidades, cidades e povoados para serem incorporadas como força de trabalho na indústria de munições. O Ministério de Munições, em Seção de Saúde e Assistência Social oferecia atividades recreativas para essas jovens tais como danças e bailes, natação e também futebol. Durante os vas para essas jovens tais como danças e bailes, natação e tambem futebol. Durante os nas o preconceito dos homens impediu o desenvolvimento do futebol de mulheres? Ver FIFA. FIFA 1904-2004: um siglo de de fútbol. Madri: Pearson Educación, 2004. Consultar especialmente o capítulo Las mujeres y los jóvens, p.182-201.

Movimento, Porto Alegre, v.12, n. 03, p. 165-191, setembro/dezembro de 2006. 
dos os cassinos que assim permanecem até hoje. Pensamos que se os homens tivessem decidido fazer GRD ou Nado Sincronizado (balé aquático) possivelmente teriam sido proibidos. A proibição diz respeito a uma peculiar distinção entre o público e o privado, aos ideais de construção social com participação ou sem ela, às liberdades dos indivíduos, sejam homens ou mulheres. Assim, na questão da proibição o aspecto de gênero não parece ser o prioritário, pois não ilumina o modo de funcionamento do poder. Apenas se denuncia para abrir um mercado de participação igualitária.

Em segundo lugar, os homens estavam divididos em relação à pratica esportiva por parte das mulheres e especialmente do futebol. Já Spencer, com toda sua enorme influência, tinha-se manifestado a favor do esporte para as mulheres. Como reconhecia que existiam preconceitos na sociedade, aceitava a ginástica enquanto mal menor diante da inatividade (Lovisolo, 1997). No caso do Brasil, Goellner (2003), tomando como base a Revista de Educação Física (1932-1945), salienta a presença de posições contrárias à prática do futebol pelas mulheres e favoráveis com adaptações. ${ }^{23} \mathrm{O}$ Dr. Humberto Ballariny parte da não inferioridade física da mulher. Entretanto, a diferença funcional, a missão, a maternidade, a beleza são valores contrários aos vigentes no futebol. Assim, o futebol seria "anti-higiênico" e contrário "à natural inclinação da alma feminina”. Parece claro que Ballariny apenas elabora a imagem e os papéis das mulheres, com seu lugar central na reprodução e na criação dos fillhos e por oposição, embora nem sempre explicitada, ele está elaborando a dos homens. ${ }^{24}$ Se o fute-

\footnotetext{
${ }^{23}$ Em artigo posterior, Goellner (2005) matiza suas posições a partir do reconhecimento de que as mulheres há muito tempo protagonizam histórias no futebol. Avança, pois reconhece a necessidade de ressigificar o espaço a ser conquistado do futebol, embora afirme que "esse espaço também é seu". Pensa o futebol como "um território ainda a conquistar". A imagem guerreira pareceria indicar que a perspectiva de gênero feminista, no caso, se tornou masculina, guerreira, machista. De tanto criticar ao "inimigo" com ele se iguala?

${ }^{24}$ Masculinidade e feminilidade, independente do que significam, não podem deixar de serem relacionais como construções identitárias.
}

Movimento, Porto Alegre, v.12, n. 03, p. 165-191, setembro/dezembro de 2006. 
bol, no passado, foi um lugar privilegiado de formação da masculinidade, parece lógico fechar suas portas para as mulheres e para a construção da feminilidade. Ignácio Loyola escreve no mesmo contexto e no mesmo periódico, a Revista de Educação Physica, que o Dr. Humberto Ballariny. Loyola apresenta seus argumentos cotejando as posições de Georges Herbert, criador do Método Natural, e Maurice Bolgey. Loyola diz que, para Herbert, nada justificaria restringir exercícios físicos às mulheres. Poder-se-ia pensar que a diferença entre os corpos de homens e mulheres era um produto negativo da civilização, pois, em tempos remotos, homens e mulheres praticariam atividades semelhantes. Bolgey contestava a igualdade com base nos conhecimentos de fisiologia da época, e afirmava peremptoriamente que a natureza fisiológica da mulher era diferente. Assim, os exercícios físicos e os esportes com características violentas (boxe, futebol, etc.) deveriam ser proibidos por não se adequarem à natureza feminina no estágio da evolução que se encontrava. Loyola diz que ambas as posições são extremadas; assim ele pensa que o problema não era a atividade em si, mas sua adequação as condições físicas e morfológicas das mulheres. Sua preocupação higienista indicava que o futebol, como esporte, desenvolvia qualidades (morais e físicas) e deveria ser praticado pelas mulheres desde que as regras e a estrutura do jogo fossem modificadas para atender a natureza física da mulher brasileira.

Além disso, alguns preceitos deveriam ser seguidos em nome da saúde e da higiene: realizar avaliação das condições físicas; praticar exercicios compensatórios para que o futebol não cause desarmonia nas formas femininas. isto é, o desenvolvimento dos membros inferiores em demasia e realizar abluções corporais. (PEREIRA, 2000, p. 48-9)

Observamos que as atividades de avaliação e compensação foram incorporadas ao treinamento moderno de homens e mulheres e que as proporcionalidades das formas, o equilíbrio morfológico,

Movimento, Porto Alegre, v.12, n. 03, p. 165-191, setembro/dezembro de 2006. 
é princípio que vale também para os homens (o halterofilista de perninhas delgadas é grotesco).

Goellner (2003) entende que mesmo no caso da aceitação da prática há cerceamento da participação das mulheres, pois são demasiadas as exigências diante do temor de que a prática danifique a função de reprodução em particular. ${ }^{25}$ Não é de fácil entendimento quais as demasiadas exigências que Goellner aponta, mais ainda quando avaliação e compensação, mediante exercícios e produtos químicos, se tornaram corriqueiras. Além disso, as prédicas dos higienistas, presentes nos periódicos de Educação Física na época, eram extensivas a todos os que praticavam ou desejavam praticar esportes. Hoje não é raro que se recomende a um atleta homem ioga ou dança como compensação e até capoeira para os futebolistas. O que Goellner (2003) parece não querer entender, desde uma perspectiva de gênero, é que os higienistas pretendiam e pretendem formar a população sadia, pois ela tornou-se o principal valor de construção dos estados nacionais (RABINBACH, 1992; LOVISOLO, 1997). Para os higienistas, o papel central na formação da população sadia é da mulher. Pouco importa se alguns homens estouram seus testículos no futebol, argumento usado por Goellner, (2003) o que importa é que a reprodução feminina funcione com eficácia no aumento da população sadia e isto significa, sobretudo, crianças saudáveis. ${ }^{26}$ De fato, o higienismo prioriza a mulher em sua intervenção, da mesma forma que os atuais programas contra a pobreza dizem: temos que dar

${ }^{25}$ Goellner (2003) parece entender que a maternidade, a reprodução, pertença ao código sexual. Não se entende sua afirmação. De ato, o valor outorgado à maternidade faz do sexo, necos um meio para um bem social, religloso, moral etc. A concepção sem sexo, mediante fertilização laboratorial e seleção dos espermatozoides, salienta a contingência do ato sexual na reprodução. Também não fica claro o "cerceamento" pelas exigências que não são descritas.

${ }^{26}$ Ver Afonso Celso (1997), no livro "Porque me ufano de meu país", publicado no final do século XIX, fala, além das 'grandezas' da pátria amada, da necessidade de crescimento da população como capital humano para povoar o imenso território e gerar mão de obra.

Movimento, Porto Alegre, v.12, n. 03, p. 165-191, setembro/dezembro de 2006. 
o dinheiro às mulheres, e não aos homens, pois elas o usam melhor. Sob o ponto de vista da genética populacional as fêmeas são mais importantes que os machos. Por isso comemos mais animais machos que fêmeas e por isso temos mais programas que tomam conta da saúde das mulheres do que dos homens e, talvez por isso, as mulheres usam mais o sistema de saúde do que os homens e, talvez, como resultado das preocupações dos homens as mulheres vivem mais. A denúncia dos preconceitos e das limitações do controle parece pouco consistente e, mais ainda, deságua no caminho do desconhecimento. Talvez o valor dado à mulher fechou-lhe as portas do serviço militar. Seus ventres eram por demais importantes para que morressem nas batalhas na época.

Mourão e Morel (2005) destacam que durante o Estado Novo a imprensa tratava de forma jocosa o futebol feminino, especialmente pela falta de técnica e pelas brigas entre as jogadoras. Essa forma de tratamento continuou ainda nos anos noventa, o que levou as autoras a afirmar: "O que se observa nas reportagens são metáforas polissêmicas e irônicas que ridicularizam a presença feminina em campo" (MOURÃO E MOREL, 2005, p. 79). Contudo, é de reconhecer que a "jocosidade" pode ser uma forma inicial de integração. Rirmos do outro ou de nós mesmos, explicitamente, é uma forma de aceitação. Em outros termos, as piadas podem se tornar um caminho de aceitação ou de administração dos conflitos. A sociedade fez isso com os homossexuais e parece que as piadas sobre eles estão diminuindo em quantidade e qualidade, ou seja, são cada vez menos numerosas e jocosas. Há uma longa literatura antropológica sobre a jocosidade que a perspectiva feminista não deveria esquecer, caso contrário fica apenas a reivindicação de reconhecimento da igualdade, embora a diferença salte aos olhos. A descrição se torna delgada, pouco densa e, então, a pretensão de gerar novos sentidos se frustra.

Em terceiro lugar, sob a perspectiva de gênero, vários autores parecem se sentir incomodados quando a mídia aponta a beleza, a graça ou a feminilidade das atletas (SIMÕES, CONCEIÇÃO,

Movimento, Porto Alegre, v.12, n. 03, p. 165-191, setembro/dezembro de 2006. 
NERY, 2004; ROMERO, 2004; KNIJNIK e SOUZA, 2004). Parecem se sentir incomodados ainda quando conjuntamente também se destaca a habilidade técnica. ${ }^{27} \mathrm{O}$ discurso assume tons de denúncia, fala de estereótipos, de preconceitos, de desvalorização. É evidente que o jornalismo esportivo foi feito dominantemente por homens, embora seja crescente a participação feminina. ${ }^{28}$ Além do bom senso que indica que nesse campo os jornalistas não poderiam elogiar a beleza masculina, existem razões mais sérias. ${ }^{29} \mathrm{~A}$ insistência sobre a qualidade de beleza, de feminilidade, e até sobre a vaidade feminina, exorciza o medo da masculinização da mulher que parece significar a perda de identidade do homem. A identidade se constrói relacionalmente em oposição. Se as mulheres podem ser másculas, que será dos homens? O medo da masculinização parece adquirir sua expressão máxima em relação à mulher homossexual. Devide (2004) analisou o impacto sobre a natação feminina brasileira da masculinização das nadadoras da Alemanha Oriental. As mulheres brasileiras pareciam ter que escolher entre serem mulheres, segundo os padrões da cultura brasileira, ou serem atletas do pódio. Mas, o dilema tem valor? É necessário usar a tecnologia, bioquímica e de treinamento, elaboradas inicialmente para os homens nas mulheres, abandonando imagens e valores sobre o corpo feminino, com destaque para a proporcionalidade? Ou seria desejável encontrar um caminho de menor sacrifício, outra tecnologia de treinamento?

No caso do tênis, podemos lembrar os comentários, as sus-

\footnotetext{
${ }^{27}$ O programa de debate e variedades, Saia Justa, exibido atualmente na GNT-Brasil, é apresentado por mulheres que muitas das vezes destacam a beleza física masculina de atores, atletas e personalidades em geral.

${ }^{28} \mathrm{~A}$ presença masculina nas editorias esportivas ainda é quantitativamente superior.

${ }^{29} \mathrm{O}$ elogio a beleza masculina poderia ser visto pela a maior parte dos consumidores do espetáculo esportivo no Brasil como uma atitude homossexual ou gay, por essa razão, os espetáculo esportivo no Brasil como uma atitude homossexual ou gay, por essa razão, os jornalistas, por vezes, usam artifícios como 'elegante' e outros qualificativos. É evidente
que há transformações em curso, mas o campo dos esportes em termos gerais ainda que há transformações em curso, mas o campo dos esportes em termos gerais ainda
trabalha com a divisão e a oposição estrutural entre homens e mulheres. Veja-se atualmente a polêmica em torno das mulheres que se transformaram em árbitras da primeira divisão do futebol.
}

Movimento, Porto Alegre, v.12, n. 03, p. 165-191, setembro/dezembro de 2006. 
peitas sobre a sexualidade de Martina Navratilova. ${ }^{30}$ Anos depois, temos tenistas de elite de técnica apuradíssima que são apresentadas como representantes da beleza, algumas delas modelos e outras rainhas das quadras, como as irmãs Willians, que parecem afirmar: somos mulheres e jogamos um tênis de excelentíssimo nível. ${ }^{31}$ Ainda mais, as atletas parecem estar disseminando novos padrões de beleza. O corpo atlético se distancia consideravelmente dos modelos femininos que parecem sofrer de anorexia. ${ }^{32} \mathrm{O}$ corpo da atleta não sofre das restrições agudas de controle de peso do corpo da bailarina clássica, restrições que se alastraram e se intensificaram em relação ao corpo das modelos. Contudo, está-se tornando um corpo cuidado, feminino, belo, desejado e que não se contrapõe ao ideal de maternidade, como a mídia sempre destaca no esforço de conciliar esporte feminino e feminilidade. ${ }^{33}$ Talvez a conciliação represente a permissão social para que a atleta habilidosa e masculinizada, seja homossexual ou não, também participe do esporte. Assim, se está socialmente dizendo: temos isto e aquilo. Podemos ter esportistas masculinizadas e feminilizadas, sem que isso indique diretamente a opção sexual. Em outras palavras,

30 "Martina sempre surpreendeu por sua coragem de falar sobre a própria homossexualidade em um meio reconhecidamente apavorado com o assunto. Muitos atletas gays não têm o menor problema com sua própria homossexualidade - o problema, eles dizem, é com os patrocinadores". Ela foi a primeira atleta famosa a declarar-se lésbica, no começo da década de 1980. É uma das maiores ganhadoras de prêmios e de Grand Slams na história do tênis profissional. Ver a coluna Vange Leonel em http://mixbrasil.uol.com.br/ cio2000/grrrls/martina.shl. Acesso em 2 de dez. 2005. Vale lembra, as mudanças que se operam em várias sociedades podem levar a um processo totalmente inverso, isto é, assumir-se homossexual pode vir a ser um bom mote para patrocinadores investirem num mercado que se apresenta cada vez mais segmentado por gostos e identidades.

${ }^{31}$ Sem dúvidas há uma forte demanda de mercado para homens e mulheres esportistas considerados belos e heterossexuais, expressivos e simpáticos. Eles se tornam considerados belos e heterossexuais, expressivos e simpáticos. Eles se tornam campeões da midia e podem ocupar mais espaço que um atleta tecnicamente superior, porém, que não reune essas características. De novo o mercado, em suas mudanças, impõe suas condições. Isto é ruim? Responder significa analisar efeitos, não apenas reagir mo-
ralmente à hipocrisia suposta, no estilo de Rousseau. ralmente à hipocrisia suposta, no estilo de Rousseau.

${ }^{32} \mathrm{O}$ corpo feminino atlético enquanto objeto de desejo e admiração talvez seja o melhor tratamento social para a anorexia.

${ }^{33}$ Varias atletas do Voleibol brasileiro e de outros esportes são noticiadas quando vivem o período da maternidade dentro e fora da prática esportiva.

Movimento, Porto Alegre, v.12, n. 03, p. 165-191, setembro/dezembro de 2006. 
está se dizendo: o esporte por si só não define a sexualidade nem o comportamento social da mulher. A conciliação se confirma na seleção das atletas midiáticas.

No caso do futebol, parece evidente que houve uma estratégia de escolher jogadoras belas, bonitas e se possível mães, para exorcizar o medo da masculinização. Não cremos que isto seja preconceito ou desvalorização, forma apenas parte do estoque de recursos que temos para incorporar o novo. O papel da mídia, nesse sentido, foi fundamental e merece uma análise mais fina. ${ }^{34}$

Lembramos, como homenagem final, o filme "Um time muito especial", dirigido por Liliana Calvani. ${ }^{35} \mathrm{O}$ filme conta a historia da formação dos times femininos de beisebol nos Estados Unidos da América durante a guerra, quando os jogadores homens estavam no front. Os 'olheiros' ${ }^{36}$ que formaram os times escolheram as jovens pela suas habilidades técnicas, havia mulheres belas, femininas, feias, másculas, gordas e magras. Os organizadores tentaram que as mulheres jogassem como senhoritas das classes médias bem comportadas. Foram submetidas a aulas de etiqueta e comportamento social, criaram-se modelos de roupas femininas e foram exigidas para que jogassem docemente. No filme, o público ri e brinca com o espetáculo, as mulheres não são levadas a sério. Feridas e iradas começam a revoltar-se e entram a jogar com tudo,

\footnotetext{
${ }^{34}$ Buscando aprofundar o debate sobre gênero no campo esportivo, realizou-se em 2005, uma série de entrevistas com um grupo de mulheres que praticam futebol no seu tempo de lazer. Estas mulheres não estão vinculadas e nenhuma equipe e/ou competição. Os jogos ocorrem semanalmente às oito horas da noite no clube Associação Atlética da Light na cidade do Rio de Janeiro. O que chama a atenção nas entrevistas e que existe uma clara preocupação na fala das mulheres praticantes de futebol de restringir a entrada de mulheres que tenham um corpo ou "jeito" masculino. Na fala dessas mulheres trata-se de um "clube familiar da Tijuca" e elas devem zelar pelo "bom andamento das partidas". A fala deixa transparecer que a preocupação com a possível masculinização do corpo da mulher que joga futebol não é exclusividade do homem. Rompe-se neste sentido com a dicotomia homem versus mulher na luta por novos espaços no futebol.

${ }^{35}$ Lembremos que L. Calvani dirigiu, entre outros, esse filme extraordinário, "O porteiro da noite". Não duvidamos que seja uma feminista ou que tenha tido um passado feminista. Menos ainda, que seja uma diretora de cinema de primeira linha.

${ }^{36}$ Termo nativo no campo do esporte para designar os selecionadores de talento.
}

Movimento, Porto Alegre, v.12, n. 03, p. 165-191, setembro/dezembro de 2006. 
não como homens, mas como mulheres que sabem jogar beisebol. Os espectadores mudam, passam a admirar e torcer pelos times. A liga é um êxito. As jogadoras não deixam de ser aquilo que são ou que desejam ser. Entretanto, no campo, são exímias jogadoras. Tanto as belas como as feias, as gordas e as magras. Anos mais tarde se reencontram na inauguração de um museu criado para lembrar a Liga e suas jogadoras. ${ }^{37}$

A mulher veio para ficar no esporte espetáculo; no mundo do esporte negócio. Já está com participação igualitária nas Olimpíadas. Agora, cremos que deve criar seus estilos, pensar seus valores, encontrar o modo de conciliar esporte e as possibilidades de expressão da mulher nesse espaço. Se apenas se trata de igualar os homens terá de assumir o ethos masculino. Não sabemos se vale a pena, diríamos que não. O que parece valer a pena é que o(a) espectador(a) passe a distinguir o esporte de mulher, a gostar dele e a valorizá-lo, algo que já vem ocorrendo em diferentes modalidades esportivas. No caso do Brasil isto já ocorreu com as diversas modalidades de voleibol, entre outros esportes. Carecemos de um bom trabalho sobre a estética no voleibol, na qual a superioridade da defesa sobre o ataque talvez crie um jogo com maiores alternativas. ${ }^{38}$

As pesquisadoras e pesquisadores da área, entretanto, se não abandonam o tom de denúncia da desvalorização e preconceito, as teses da construção e controle do feminino por parte dos homens, dificilmente conseguirão produzir o entendimento do processo cultural que almejam. Parece que chegou a hora de pensar sobre o que fazer com aquilo que foi "conquistado", ao invés de, de forma repetitiva, insistir sobre os territórios a conquistar. $\mathrm{O}$

${ }^{37}$ Ver as análises de Soares (2006) e Guedes (2006) sobre o filme Bend it's like Beckham (Driblando o destino). Os autores analisam as tensões étnicas e de gênero que aparecem como eixos narrativos no referido filme.

${ }^{38}$ Agradecemos o Professor Guilherme Pacheco os comentários sugestivos sobre o tema.

Movimento, Porto Alegre, v.12, n. 03, p. 165-191, setembro/dezembro de 2006. 
tempo da lamúria está acabando. Carecemos de um tempo de construção e de discussão mais aprofundada do valor das práticas nas quais mulheres e homens estão inseridos. Por fim, os estudos de gênero parecem estar enfiados num paradoxo: por um lado, reivindicam uma espécie de igualitarismo absoluto através do "cotismo", por outro, afirmam a diferença em termos epistemológicos e de direitos sociais que, por vezes, retomam como única opção o argumento das diferenças. $\mathrm{O}$ problema da segunda sentença do paradoxo é que os argumentos, identitários ou de gênero, parecem estar crescentemente assentados nas diferenças biológicas entre homens e mulheres. ${ }^{39}$ Estaríamos, portanto, abandonando a perspectiva do poder e da cultura em benefício das diferenças naturais? O feminismo estaria caminhando do culturalismo descontrutivista e crítico na direção do naturalismo universalista? Se esta for a direção, grande parte do escrito sob o ponto de vista do gênero sobre o esporte, e sobre o futebol em particular, deverá ser revisto.

39 Os agudos comentários de Badinter (2005) sobre o que ela chama de "armadilha" do discurso feminista.

Movimento, Porto Alegre, v.12, n. 03, p. 165-191, setembro/dezembro de 2006. 
Feministas, Mujeres y Deportes: cuestiones metodológicas

Resumen: Este artículo discute aspecto de la perspectiva crítica particularmente relevantes en el debate sobre género: denuncia, "cuotismo" y efectos epistemológicos o de conocimiento, a partir del debate instalado sobre la participación femenina en el fútbol. La elección de este deporte se debió al motivo de ser el más importante para la cultura brasilera y, sobretodo, porque autores y autoras invirtieran criticando representaciones, prácticas cuyas formas de participación serían controladas por los hombres. Concluyese observando que más allá de la crítica o de la denuncia a la discriminación, basada en el 'cuotismo', no existe la emergencia de novedades de conocimiento a partir de la perspectiva de género.

Palabras clave: Feministas; Deportes; Equidad; Identidad de género.

Feminist, Women and Sports: Methodological questions

Abstract: The aim of this article is discuss the relevant aspects about Women's soccer participation in Brazil from the perspective gender's debate. The main point's analyses in the gender's sports literature will be: discrimination, quota system and epistemological or knowledge effects. We will use soccer because it is the most important sport for the Brazilian culture and, above all, because authors invested criticizing representations, practices and that the participations are ways controlled by men. We conclude that, besides the discrimination or accusation critic, based on quotas reservoir, there is not the emergency of novelties of knowledge from the gender perspective.

Keywords: Feminist; Sports; Equality; Gender Identity. 


\section{REFERÊNCIAS}

ALABARCES, P. Fútbol y patria: el fútbol y las narrativas de la nación en la Argentina. Buenos Aires: Prometeu Libros, 2002.

ARCHETTI, E. Masculinidades, fútbol, tango y pólo en la Argentina. Buenos Aires: Antropofagia, 2003.

BADINTER, E. O rumo equivocado. Rio de Janeiro: Editora Civilização Brasileira 2005

CELSO, A. Porque me ufano de meu país. Rio de Janeiro: Expressão e Cultura, 1997.

DEL PRIORE, M, Corpo a corpo com a mulher. São Paulo: Ed. Senac, 2001.

DEVIDE, F.P. História das mulheres na natação, ascensão e permanência no comando de equipes esportivas de alto nível. In: SIMÕES, A. C.; KNJNIK, J. D. (org). O Mundo psicossocial da mulher no Esporte: comportamento, gênero desempenho. São Paulo:ALEPH, 2004. p. 319-336.

ELUF, L. N. Três questões sobre feminismo. Folha de São Paulo, São Paulo, 15 de out. de 2000. Caderno Mais, n. 453, p 3.

EISENBERG, C. et al. A FIFA 1904-2004. Un siglo de. fútbol. Madrid: Pearson Educación, 2004

GOELLNER, S.V. Bela, maternal e feminina: imagens da mulher na Revista Educação Physica. ljuí: Editora Unijuí, 2003

GOELLNER, S.V. Mulheres e futebol no Brasil: entre sombra e visibilidade, Revista Brasileira de Educação Física, São Paulo, v.10, n.2, p.143-152, 2005

GOLDEMBERG, M. (Org.) Os Novos Desejos. Das Academias de Musculação às Agências de Encontros. São Paulo: Record, 2000.

GUEDES, Simoni Lahud. A construção do corpo masculino nas escolinhas de futebol. In: GUEDES, Simoni Lahud. O Brasil no campo de futebol: estudos antropológicos sobre os significados do futebol brasileiro. Niterói: Eduff, 1998. p. 117-136. (Antropologia e ciência política).

GUEDES, Simoni Lahud. Um dom extraordinário ou "cozinhar é fácil, mas quem sabe driblar como Beckham: comentários sobre o filme driblando o destino. In MELO, V. A de; ALVITO, M. (org.). Futebol por todo mundo: diálogos com o cinema. Rio de Janeiro: FGV, 2006. p. 41-53.

HTUN, M. Evaluating the Results of Quota Systems in Politics in Latin America Rev. Estud. Fem. [online], v.9, n.1, p.225-230, 2001. Disponivel em: < http $/ /$ www.scielo.br/scielo.php?script $=$ sci_arttext\&pid $=50104$ $6 \times 2001000100013 \&$ Ing=en\&nrm=iso>. Acesso em: 02 Dez 2005.

KNIJNIK, J.D. A mulher brasileira e o esporte. São Paulo: Mackenzie, 2003.

Movimento, Porto Alegre, v.12, n. 03, p. 165-191, setembro/dezembro de 2006. 
KNIJNIK, J.D.; SOUZA, J.S. Mulheres ao mar: surfe e identidade femininas em transição. In: ___. (org). O Mundo psicossocial da mulher no Esporte: comportamento, gênero, desempenho. São Paulo: ALEPH, 2004. p. 253-276.

KUPPER, Adam. Cultura: a visão dos antropólogos. Bauru: EDUSC, 2002.

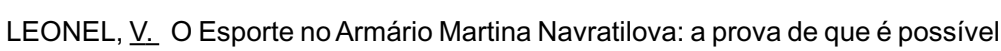
ser gay assumido no esporte. MixBrasil - Bolacha llustrada. Disponível em: <http://mixbrasil.uol.com.br/cio2000/grrrls/martina.shl .>Acesso em: 2 de Dez. 2005.

LOVISOLO, H. Estética, esporte e educação física. Rio de Janeiro: Ed. Sprint, 1997.

LOVISOLO, H. História oficial e história crítica: pela autonomia do campo. In: VI Congresso Brasileiro de História do Esporte, Lazer e Educação Física, 1998, Rio de Janeiro. Anais do VI Congresso Brasileiro de História do Esporte, Lazer e Educação Física. Rio de Janeiro: Editora Gama Filho, 1998, p. 54-64.

LOVISOLO, H. Sociologia do esporte: viradas argumentativas. In: Encontro Anual da ANPOCS, Anais do $26^{\circ}$ Encontro Anual da ANPOCS. Caxambu, ANPOCS, 2002. 1 CD-ROM, GT 06

MITCHELL, J. Folha de São Paulo, Caderno Mais, n. 453, p. 5-8, 15 de out. 2000. Entrevista concedida a M.L. Pallares Burke.

MOURÃO, L. Representação social da mulher brasileira na atividade físicodesportiva: da segregação á democratização. 1998. 304 f. Tese (Doutorado em Educação Física) - Programa de Pós-graduação em Educação Física, Universidade Gama Filho, Rio de Janeiro, 1998

MOURÃO, L.; GOMES, E.M. Mulheres na administração esportiva brasileira: uma trajetória em curso. In: SIMÕES, A.C.; KNJNIK, J. D. (org). O Mundo psicossocial da mulher no Esporte: comportamento, gênero, desempenho. São Paulo: ALEPH, 2004, p. 305-318.

MOURÃO, L.; MOREL, M. As narrativas sobre o futebol feminino: o discurso da mídia impressa em campo. Rev. Bras. Cienc. Esporte, Campinas, v. 26, n. 2, p. 73-86, jan. 2005

MURARO, R. M. Três questões sobre feminismo. Folha de São Paulo, São Paulo, 15 de out. de 2000. Caderno Mais, n. 453, p 3.

PEREIRA, L.A.M. Footballmania: uma história social do futebol no Rio de Janeiro. Rio de Janeiro: Nova Fronteira, 2000

RABINBACH, A. The Human Motor. Los Angeles: University of California-Berkeley, 1992.

ROMERO, E. A (in)visibiliade da mulher atleta no jornalismo esportivo do Rio de Janeiro. In: SIMÕES, A. C.; E KNJNIK, J. D. (org). O Mundo psicossocial da mulher no Esporte: comportamento, gênero, desempenho. São Paulo: ALEPH, 2004. p. 213-252.

Movimento, Porto Alegre, v.12, n. 03, p. 165-191, setembro/dezembro de 2006. 
SEBRELI, J. Fútbol e massas. Buenos Aires: Galerna, 1981.

SIMMEL, G. Sobre la aventura: ensayos de estética. Barcelona: Península, 2002.

SIMÕES, A.C.; CONCEIĈ̃̃ P.F.; NERY, M.A. Mulher, esporte, sexo e hipocrisia In: SIMÕES, A. C.; E KNJNIK, J. D. (org). O Mundo psicossocial da mulher no Esporte: comportamento, gênero, desempenho. São Paulo: ALEPH, 2004, p. 61-87.

SOARES, A. J. Diálogos identitários - etnia, gênero, sexualidade e futebol: comentários do filme driblando o destino. In: MELO, V. A. de; ALVITO, M. (Org.) Futebol por todo mundo: diálogos com o cinema. Rio de Janeiro: FGV, 2006, p. $55-68$.

Movimento, Porto Alegre, v.12, n. 03, p. 165-191, setembro/dezembro de 2006. 